\title{
LA INCIDENCIA DE LA MUERTE EN LA FORMACIÓN DE LOS SENTIMIENTOS MORALES DE SMITH A LA LUZ DE LA ÉTICA DE LÉVINAS
}

\author{
Cécile Furstenberg \\ Universidad Católica de Chile \\ cecilefurstenberg@yahoo.fr
}

\begin{abstract}
Resumen / Abstract
A la luz de la ética de Lévinas, donde la muerte es presente y central en el concepto de responsabilidad fundamental para salvaguardar la humanidad, se puede observar la incidencia de la muerte en la formación del sentimiento y juicio moral en los escritos de Smith. La valoración del papel de la muerte en la teoría de los sentimientos morales mediante este estudio comparativo permite poner de relieve la función del cuidado de sí y del otro que subyace en su teoría y percibir sus aportes posibles en las reflexiones y los debates éticos relacionados con la muerte y la vida.
\end{abstract}

Palabras Clave: Lévinas, Smith, muerte, ética, sentimientos morales.

\section{THE IMPACT OF THE DEATH IN THE FoRMATION OF MORAL FEELINGS OF SMITH IN THE LIGHT OF LEVINA'S ETHICS}

In the light of Levinas's ethics, where the death is present and central in the concept of fundamental responsibility to safeguard the humanity, it's possible to observe the incidence of the death in the formation of the feeling and moral sense in Smith's writings. The valuation of the role of the death in the theory of the moral feelings thanks to this comparative study allows to emphasize the function of oneself and another's care that underlies his theory and to perceive his possible contributions in the reflections and the ethical debates related to death and life.

KEY WORDS: Levinas, Smith, death, ethics, moral.

\section{Introducción}

$\overline{\mathrm{RA}}$

La muerte es un tema de reflexión recurrente en la historia de la filosofía. La muerte nos invita a repensar y adaptar la vida, para sí y con los demás, en función de nuestra condición mortal. Desde la Antigüedad, la muerte y el muerto merecen consideración. La tragedia Antígona de Sófocles presenta la ley natural de la sepultura del muerto como manifestación de respeto y dignidad debida al hombre muerto. Platón relata la muerte de Sócrates en el Fedón. Los estoicos recomiendan desprenderse del temor de la muerte para vivir plenamente el presente. Montaigne declara que "philosopher 
c'est apprendre à mourir" "Filosofar es aprender a morir" (trad. personal). Autores contemporáneos prosiguen indagando al respecto; así Echeverría en "El morir como pauta ética" (2013) fue "filósofo de una vida reflexiva que asume la muerte como un momento suyo" ${ }^{2}$. Cada uno se ha encontrado o se encontrará, tarde o temprano, enfrentado con esta realidad de la muerte para sí o para el otro. En la sociedad actual los problemas éticos sobre los derechos relativos a la vida y a la muerte en cuanto a la conducta ética o legislación bioética siguen vigentes.

Lévinas, confrontado durante la segunda guerra mundial con la muerte masiva y el problema del mal llegando a su extremo, tanto en su vida personal como contextual, funda su ética en la responsabilidad por y para el otro, mi prójimo. Si la responsabilidad se enraíza en la realidad del encuentro con el otro presente, la posibilidad de la muerte del otro da a la responsabilidad mayor peso. "La muerte del otro me pone en cuestión como si, en esta muerte invisible del otro que se expone, llegaría a ser, en mi indiferencia, el cómplice; y como si aun de serle entregado por mí mismo, tuviera que responder de esta muerte del otro y no dejar otro solo a su soledad mortal" (A.T., 46, trad. personal).

En la Teoría de los Sentimientos Morales de Adam Smith y otras de sus obras hay de vez en cuando reflexiones o comentarios respecto de la simpatía hacia los muertos, del pavor frente a la muerte o de la relación entre justicia y la muerte que merecen ser destacados. Según las lecturas habituales de la Teoría de los sentimientos morales, las relaciones entre los seres humanos vivos forman los sentimientos morales. Sin embargo se encuentra por ejemplo: "Y así surge uno de los principios más importantes de la naturaleza humana, el pavor de la muerte, el gran veneno de la felicidad humana pero el gran freno ante la injusticia humana, que aflige y mortifica al individuo pero resguarda y protege la sociedad" (T.S.M., 56).

Si se procede a una lectura atenta de los distintos escritos de Adam Smith, la muerte, como marca indeleble de la precariedad de la naturaleza humana, tiene una incidencia concreta en la formación de los sentimientos morales. Se escudriñará en los escritos de Smith sus aportes respecto del tema, partiendo de las reflexiones sobre la muerte, ampliamente desarrolladas, en los escritos de Lévinas. Ambos autores concuerdan en algunos aspectos, se diferencian en otros y además abordan este tema desde una perspectiva distinta: empírica para Smith y fenomenológica para Lévinas. Estos horizontes divergentes permiten enriquecer las reflexiones en los debates éticos relativos a la muerte y a la vida.

Montaigne 2009. Essais. Paris: Broché. Livre I, chapitre XIX.

Humberto Giannini, El Mercurio, 25 de junio de 1998. Livre I, chapitre XIX. 


\section{¿Qué es la muerte, cómo se define?}

Lévinas describe la muerte como se presenta en el plano biológico, marcando el quiebre ineluctable con la vida de la cual significa el término. "La muerte es separación irremediable: los movimientos biológicos pierden toda la independencia respecto al significado, la expresión. La muerte es descomposición: es la no respuesta" (DMT, 22). Feron (1999, p. 46) subraya los dos rasgos dominantes de la muerte descrita por Lévinas, la muerte es: "la no respuesta" y "la partida sin vuelta hacia lo desconocido". Feron añade que Lévinas recalca que toda muerte no puede sustraerse a su carácter dramático, es un desgarre doloroso en la relación con el otro. La muerte no pertenece, según Lévinas, al mundo. Si bien Lévinas se refiere a la descripción de la tradición filosófica que, según la creencia, describe la muerte como el paso a la nada, o como el paso a otra existencia, luego, relaciona la muerte con la alteridad. La muerte es algo totalmente distinto que implica la alteridad: "Así la relación con el misterio o la incógnita de la muerte es la relación con el otro" (DMT, 272). Lévinas, entonces, no confirma la correspondencia entre la nada y la muerte que siendo alteridad, es otro, y es para sí apertura a lo Infinito. El otro en su alteridad absoluta es transcendente. Lévinas recuerda que la trascendencia es la expresión de un movimiento a través (trans) y un movimiento hacia arriba (scando). Además, Lévinas inscribe la posibilidad de la muerte como interna a la vida y deja la nada de la muerte como pregunta, "un puro signo de interrogación" (DMT, 134). Esta misma pregunta de la nada de la muerte no "sería nunca posible sin que se produzca la relación con el prójimo y el signo de interrogación de su rostro" (DMT, 135). Lévinas encarna la muerte en el rostro, el prójimo que siendo vivo lleva en su "desnudez" la marca de la muerte. "¿La nada de la muerte no es la propia desnudez del rostro del prójimo?” (DMT, 138). La muerte presenta en sí una amenaza para la vida, la suya y la del prójimo.

Smith recuerda la trivialidad aparente de la condición mortal del hombre:

Decir que "todos los hombres están sujetos a la muerte", presenta solo una idea vulgar, pero esto se eleva y llena la imaginación, cuando es pintado así por Horace: "Con paso igual, Puñetazos de destino imparciales en el palacio, como la puerta de casita de campo. O debemos pisar los caminos de saciedad; y alguna vez sacude la urna mortal; la parte entera nos embarca, tarde o temprano, En el barco de Charon; ¡ah! No volver jamás" (Lectures on rethoric and belles lettres, 1963, 360-361, trad. personal).

Smith considera que la muerte es, en su forma natural, "una conclusión de la edad avanzada como la juventud lo es de la infancia o la vida adulta de la juventud" (T.S.M., 490). Smith dice que la propensión natural del hombre es considerarse primero con sus propios intereses, la preocupación y el cuidado de sí. El hombre puede volverse poco sensible a la muerte de los demás, aún más si son desconocidos (T.S.M., 177178). En cuanto a la muerte propia recuerda una cita de Epicuro que "decía: cuando existimos, la muerte no existe, y cuando la muerte existe, no existimos; por tanto, la muerte no significa nada para nosotros" (T.S.M., 502). Smith no se expande en pensar fenomenológicamente la muerte, describe la gravedad del hecho concreto de 
la muerte como término irremediable de la vida, esto no deja indiferente y apela a los sentimientos morales. Smith reitera en la Teoría de los Sentimientos Morales que la muerte es lo peor que puede suceder al hombre que sea en forma natural o infligida por otra persona, ya que sustrae al hombre de la vida activa. "La muerte es el máximo mal que una persona puede infligir a otra y estimula el mayor grado de rencor entre los más inmediatamente allegados al fallecido" (T.S.M., 178). La consideración de la muerte implica los sentimientos morales y Smith analiza la muerte a partir de los afectos, del resentimiento, y muestra la necesidad de recurrir a la justicia.

Para ambos autores, la muerte es una realidad ineluctable de la naturaleza humana que no deja de ser trágica y dramática, ya que es una partida definitiva de la persona activa. Lévinas integra la muerte en la ética y Smith en los sentimientos morales. Lévinas integra la muerte de manera central y latente, no solo como hecho, sino también como posibilidad que ordena a la responsabilidad. Smith evoca la muerte en situaciones concretas reales, describiendo el proceso moral que se deduce cuando muere alguien en función del contexto.

\section{¿Cómo se da la experiencia de la muerte para el sujeto?}

Para Lévinas, el "encuentro" con la muerte se puede observar en el otro. La experiencia de la muerte nunca puede ser propia sino observada por otro.

"Alguien que muere: un rostro 3 que se convierte en máscara. La expresión desaparece. La experiencia de una muerte que no es la mía es la "experiencia" de la muerte de alguien, uno que, de golpe, está más allá de los procesos biológicos, que se relaciona conmigo con forma de alguien" (DMT, 23).

El modo de la experiencia personal de la muerte del otro va a ser la sustitución: "Simpatía o compasión, tener mal para el otro o «morir mil muertes» para el otro tienen por condición de posibilidad una sustitución más radical a otro" (MT, 44, trad. personal). Lo que el lenguaje nombra muerte y es como la experiencia del fin de alguien es "una eventualidad que puede transferirse a sí-mismo" (M.T, 44, trad. personal). Este transferencia no es exactamente vivir la muerte del otro en su lugar: "El rostro del que muere, muriendo se asocia a mí, me interpela y me convoca y es bien en esta expresión que reside la transferencia evocado por Lévinas" (Feron, 1999, 62, trad. personal)). La muerte no solo puede ser descrita, sino también pensada. El muerto entonces no es más un cuerpo, una cosa sino "una sombra" (T.A., 103). Lévinas no desvincula las emociones de la experiencia de la muerte del otro (DMT, 126). El encuentro con la muerte del otro

3 El rostro para Lévinas: "El rostro es presente en su rechazo de ser contenido" (T.I, 211, trad. personal). "La relación con el rostro puede es cierto ser dominado por la percepción, pero lo que es específicamente el rostro, es lo que no se reduce a ello" (E.T., 80, trad. personal). 
se revela en mi forma de acoger al prójimo presente. En este pensamiento, que llega a ser sustitución de la nada de la muerte del otro se expresa la necesidad de "volverla inofensiva (...) justificarla o prometerle la vida eterna" (T.A., 130, trad. personal). La respuesta de la sustitución obliga al yo, haciéndose cargo del muerto, de responder por el de los otros: el otro confía en mí y me pide decir la respuesta que daba a los demás, su responsabilidad. A pesar de que la concreción de la experiencia de la muerte pase por el otro, Lévinas sostiene que existe un conocimiento instintivo de la muerte independiente de toda experiencia razonada de la muerte del otro. Mi muerte no se deduce por analogía de la muerte de los demás, sino que se inscribe en un miedo que puedo tener para mí ser. Lo que define la amenaza no es tanto el saber de la muerte sino más bien "la inminencia de la muerte, en su irreductible movimiento de cercanía" (T.I, 259, trad. personal). El miedo mide este movimiento de cercanía a la muerte que conserva un carácter imprevisible. La responsabilidad como respuesta a esta pregunta ansiosa de la nada de mi muerte posible es lo que me permite salir de la soledad.

Para Smith, la experiencia de la muerte del otro se realiza mediante la simpatía. La simpatía hacia los muertos es un tipo de simpatía especial denominada "simpatía ilusoria" : "nos ponemos en su lugar y alojamos, por así decirlo, nuestras almas vivientes en sus cuerpos inanimados, y así concebimos lo que serían sus emociones en tal caso" (T.S.M., 54-55). Mediante la imaginación se siente una vivencia actual del cuerpo muerto lo que toca los afectos (T.S.M., 55). El dolor, los lamentos, tienden a compensar una tristeza del muerto, su malestar, pero el no poder tener una simpatía interactiva, donde los dos concernidos reajusten sus sentimientos, por el hecho que el muerto ya no es, deja aún más frustrado y aumenta la desgracia de la pérdida de la relación con el otro. La simpatía integra el contexto de la muerte, y el espectador llega por la imaginación y la emoción a sentir con el muerto "a una identificación ilusoria con ella” (T.S.M., 154). Según Dutrait (2008, 6-7), la simpatía ilusoria toma una dimensión imaginaria o sea ilusoria de la cual el principal interesado no puede tomar conciencia. Dutrait subraya la utilidad de este proceso de la imaginación (T.S.M., 55-56) que permite desarrollar el pavor por la muerte. El espectador reacciona frente a la experiencia de la muerte del otro por medio de sus sentimientos morales. "El daño sufrido demanda, a nuestro juicio, una parte muy importante de nuestra atención" (T.S.M., 154) y se debe la reparación si la causa de la muerte lo requiere. Así, para Smith el deber de reparar y condenar al culpable obedece "en alguna medida al desagravio por el mal hecho a los muertos" (T.S.M., 187).

La simpatía ilusoria puede parecer asemejarse en algo a la sustitución de Lévinas según Feron (1999, 52, trad. personal). “LLa sustitución no sería ella misma simpatía en un sentido eminente, simpatía por excelencia?". Efectivamente en ambos casos se trata de "ponerse en el lugar del otro". Lévinas apela a la asociación para expresar esta

4 Frierson (2006) pertinentemente da relieve a la simpatía con los muertos apuntando que es la conclusión de la sección una de "La teoría de los sentimientos morales", y el tercer ejemplo más desarrollado sobre la simpatía ilusoria, después del loco y el del niño, antes de dicha conclusión. 
experiencia de la muerte el otro. "Alguien muere. El rostro llega a ser máscara. La expresión desaparece. La experiencia de la muerte que no es la mía es "experiencia" de la muerte de alguien que se encuentra de antemano más allá de los procesos biológicos, que se asocia a mí bajo la forma de alguien" (M.T., 14, trad. personal). Pero la sustitución implica, para Lévinas, la condición de rehén del sujeto, que sufre para y por el otro, y no es una mera imaginación, representación del sujeto tal como ocurre en la simpatía. Esta sustitución reenvía al traumatismo de la persecución lo que incluye el sufrir por él, responder por él y expiar sus faltas. La responsabilidad además es la respuesta que reafirma la confianza y la tranquilidad frente al miedo de la muerte.

\section{¿Cuál relación tiene la muerte con el tiempo?}

Su propia muerte, según Lévinas como acontecimiento, se muestra "eterna en el futuro" (D.M.T., 272). La muerte como el futuro no se pueden aprehender. El momento de la muerte comprende un momento imprevisible que no puede ser abarcado en ningún horizonte. La muerte es esta amenaza que se acerca paso a paso, abriendo paso al misterio (T.I., 261). Dentro de este movimiento de cercanía a la muerte se introduce la paciencia y el alejamiento por el retraso de la inminencia. Lévinas pretende que la muerte se aprehende mediante la pasividad, una "pasividad más pasiva que toda pasividad" constitutiva de la subjetividad y que no puede ser síntesis del sujeto. La muerte aprieta y me deja tiempo. Parra $(2009,582)$ observa que "No solo hay una estrecha y fecunda relación entre pasividad y temporalidad, sino también entre temporalidad, pasividad y paciencia en el planteo levinasiano". La responsabilidad se inscribe en este tiempo: "Y la espera sin lo esperado (el propio tiempo) se vuelve responsabilidad hacia los otros" (D.M.T., 165). La esperanza es la apertura al porvenir y a su vez la travesía de la prueba de la realidad, o sea, presupone una desesperanza inicial. En esta responsabilidad y alteridad, el yo se abre a lo infinito. El yo está encerrado en el tiempo que transcurre desde su nacimiento hasta su muerte, vive para la muerte y contra su muerte. Al salir de su soledad y de esta amenaza de la muerte por la responsabilidad o la respuesta a la nada de la muerte, su voluntad desplaza su centro de gravedad: "para querer como Deseo y Bondad que nada limita" (T.I., 267, trad. personal). Para explicar cómo surge el infinito en la relación de responsabilidad (D.M.T, 139), Lévinas recurre a un fragmento bíblico (Gen: 18,23 y ss) en el cual Abraham intercede por Sodoma. Abraham siente la culpabilidad de sobreviviente y la necesidad de interceder, a pesar de reconocer que es "polvo y ceniza". La responsabilidad no es decisión propia, es respuesta frente al rostro del prójimo que precede todo consentimiento libre, todo contrato. "El prójimo me asigna antes que lo designe" (T.I., 174, trad. personal). En la cercanía, me hago servidor del prójimo, "ya atrasado y culpable del atraso" (T.I., 174, trad. personal). La responsabilidad se extiende hasta después de la muerte. Rolland (2000) subraya que la responsabilidad que Lévinas otorga al sobreviviente implica la culpabilidad que no es necesariamente falta, sino que es debida al "puro efecto de la irreductible alteridad de otro en su proximidad de rostro o de prójimo, la cual me mete siempre y por necesidad en retraso para la cita a la cual este me asigna" (Rolland 2000, 74, trad. personal). El 
prójimo que muere interpela al yo para que sea el guardián de la relación, y el duelo va a ser un esfuerzo para unir las relaciones, sin olvidar al otro, aunque físicamente ya no pueda responder, está muerto. "El otro que fallece me ordena guardarlo en mí no solo por el recuerdo o la memoria sino designándolo como el guardián de lo que nos une, haciendo vivir en mi la relación" (Feron 1999, 120, trad. personal). Esta relación que tengo con el otro, afectada por la muerte abre al tercero y a los otros y permite el adviento del evento del sentido.

Smith no desarrolla una fenomenología del tiempo respecto de la muerte. Smith asocia la noción de futuro a la muerte, cuando trata de la muerte propia. Al presentar la virtud de prudencia se refiere a Epicuro y explica que las sensaciones del presente pueden ser ligadas a eventos pasados o futuros. Así, el "más espantoso pavor del futuro" (T.S.M., 501) puede relacionarse con el pavor de la muerte. Después de la muerte, Smith analiza detenidamente los sentimientos que provocan en los que sobreviven la muerte y sus circunstancias. La muerte repentina provoca en las emociones una violencia importante "hasta a veces causar la muerte inmediata" (Essays on philosophical subjects, History of Astronomy, section I., trad. personal). El proceso de reacciones emocionales se desarrolla también en el tiempo y puede necesitar reparación futura. A su vez, Smith considera que los sentimientos de tristeza y el proceso de duelo, causados por la pérdida de alguien, toman su tiempo y es bueno recordar, conmemorar, dar testimonio de la vida del difunto. Así escribirá $\mathrm{Smith}^{5}$ una carta a la muerte de su amigo Hume en la que recuerda su amistad y sus últimos momentos, como si el deber de memoria hiciera parte de una necesidad moral que la muerte no vuelve inútil. Así, en su vida personal Smith describe en algunas $\operatorname{cartas}^{6}$ las relaciones privilegiadas con su madre y las recuerda después de su muerte, como preciosas y meritorias. La muerte de su madre en 1784 y la de su prima Miss Douglass en 1788 dejaron huella en la salud de Smith y él mismo reconoce que el duelo puede afectar mucho. La música, el arte según Smith ${ }^{7}$ pueden consolar. Además, West (1976, 238), refiriéndose a Smith, nota que en el duelo el contacto con los demás salva de la soledad mortal.

5 Torres Fierro, D. (2008), David Hume Adam Smith, Dos testimonios trágicos, Claves de Razón Práctica, enero-febrero 2008, n¹79: 66-70. Recuperado de: http://www.elboomeran. com/upload/ficheros/noticias/claves179tfierro2.pdf

6 Carta a William Strahan, Custom house, Edingburgh, 10 June 1784, trad. personal. "Aún debo decirle, que he dicho a otra gente, que la separación final de una persona que seguramente me amó más que cualquier persona alguna vez amó o alguna vez me amará; y quien seguramente amé y respeté más que alguna vez amaré o respetaré a cualquier otra persona, no puedo menos de sentir, aún a esta hora, como un golpe muy pesado sobre mí". Smith. A. (1982). Essays on philosofical subjects. Oxford University Press, Liberty Found Indianapolis. "Of the nature of that imitation which takes place in what are called the imitative arts". 


\section{¿En que influye el miedo de su propia muerte?}

Lévinas describe la angustia frente a la muerte, refiriéndose a la descripción de Heidegger, pero no retiene la angustia como descripción adecuada de la experiencia personal frente a la muerte que es la nada. Percibe más bien la muerte como una amenaza para sí. Esta amenaza proviene de lo desconocido, del secreto, del misterio. La amenaza del homicidio es también una realidad. La muerte como posibilidad engendra el miedo para sí de afrontarla en la soledad. Este miedo es violento, ya que parece depender de la voluntad de otro, mi voluntad no sucumbe a una necesidad, a una ley de determinismo sino que es alienada por otra voluntad. De esta amenaza surge la llamada al otro, a la amistad, al que médica, al otro de quien se teme y se espera: "El Eterno hace vivir y hace morir" (T.I., 260, trad. personal). La sociabilidad, la apertura al otro, permiten un ancla en la esperanza y un sentimiento de seguridad. La propia voluntad encuentra en la paciencia paz y alivio. "Ser consciente es tener tiempo" (T.I., 264, trad. personal). De esta paciencia surge la libertad que es: "tener tiempo para prevenir su propia decaída bajo la amenaza de la violencia” (T.I. 265, trad. personal).

En forma general, Smith hace derivar el cuidado de sí de la virtud de prudencia que permite conservar una buena salud (T.S.M. 371). Las elecciones relativas a opciones relacionadas con necesidades del cuerpo se realizan en función de "la voz de la propia naturaleza" que indica lo que se debe hacer o evitar. Campbell $(1971,178)$ observa el rol del aprendizaje para el cuidado de sí, según Smith, el aprendizaje en la niñez permite procurar adecuar, según el cuidado y la previsión, las necesidades del cuerpo. El cuidado de la salud es propio a la virtud de prudencia cuyo objetivo principal es la seguridad. El "espectador imparcial" 8 permite confirmar el esfuerzo personal y la constancia en la práctica de la laboriosidad y la frugalidad. La aprobación contempla tanto la situación actual como futura y es la del espectador imparcial, y su "representante", "el hombre dentro del pecho". Para Smith, el miedo o "pavor" de la muerte es una realidad existencial que puede ser muy importante, y será determinada por el contexto, si el pronóstico vital está comprometido, y las razones de dicha posibilidad de muerte. En cuanto al miedo de su propia muerte con la virtud de prudencia se da el "cuidado de la salud" (T.S.M., 376). Esta virtud de prudencia se traduce en la moderación, la templanza, la frugalidad, que favorecen una buena salud y puede disminuir las complicaciones y la angustia frente a la muerte. En cuanto al cuidado de sí mismo, Smith se refiere a los estoicos (T.S.M., 385). La guerra es, según Smith, la mejor escuela para aprender a domar el miedo frente a la muerte. Se necesitan, frente a la amenaza constante del peligro de la muerte, el coraje, el aprendizaje y la presencia de ánimo. Smith hace el elogio del hombre que logra enfrentar la muerte con magnanimidad hasta los últimos momentos. Dicha persona merece admiración. El dominio de sí en situaciones conflictivas

$8 \quad$ Espectador imparcial: "Lo que distingue el espectador imparcial de cualquier otra persona no son sus cualidades sino su punto de vista particular: representa las reacciones de una persona común cuando está en la posición de un espectador no involucrado"(Campbell 1971, 135, trad. personal). 
"en peligro, bajo tortura, ante la inminencia de la muerte" atrae "admiración en sumo grado" (T.S.M., 416). A su vez, el ejercicio de domar el miedo frente a la muerte será un aprendizaje muy útil para favorecer el dominio de sí y así: "Según reza el dicho: la muerte es la reina de los miedos, y no es probable que la persona que ha conquistado el terror de la muerte pierda su presencia de ánimo frente a ningún otro mal natural" (T.S.M., 417). Al tener un dolor físico agudo, Smith aconseja considerar el impacto de la memoria y del pasado, "la agónica remembranza del pasado" (T.S.M., 501), o la angustia del futuro, "el más espantoso pavor del futuro" (T.S.M., 501), para que el padecimiento del presente no sea acrecentado además de sufrimientos imaginarios que aumenten el tormento, más de lo que corresponde en la realidad actual.

Para ambos autores, el miedo a la muerte es natural y es bueno ejercitarse para que no tome, este temor o pavor o terror de la muerte, proporciones excesivas que impidan una presencia en el presente. Según Lévinas, saber afrontar el miedo a la muerte enseña la paciencia y abre a la esperanza. Según Smith, dominar el pavor de la muerte invita a una presencia de ánimo, a un coraje y a una magnanimidad que merecen admiración.

\section{¿Qué reacción induce el riesgo de la muerte del otro?}

Lévinas recuerda que en el riesgo de la muerte del otro está también inscrita la posibilidad que tengo en mi poder de matarlo. Frente a la gravedad de atentar al otro, al rostro, por lo dramático que es el hecho de la muerte, el atentado a la trascendencia o a la apertura al infinito, Lévinas invierte mediante la pasividad la mirada hacia la "epifanía del Rostro". El otro me llama a la responsabilidad y a su vez me liga con la culpabilidad. El otro me responsabiliza, nadie puede responder en mi lugar. Tengo que responder de su muerte. Mi responsabilidad hacia el otro mortal me obliga al cuidado. El otro es para Lévinas "el pobre, el extranjero, la viuda, el huérfano". La responsabilidad consiste hasta en sacarse el pan de la boca para dárselo al hambriento, vestir al desnudo (D.M.T., 227; TI, 218). "Esta asistencia, no es el neutro de una imagen, sino la solicitación que me concierne desde su miseria y su Altura" (T.I., 218, trad. personal). La responsabilidad implica no solo la respuesta "heme aquí", sino la acción adaptada a la necesidad del otro. La culpabilidad no es solo la consideración retroactiva de mi responsabilidad por lo que he hecho, para Lévinas es también sentirse culpable por el atraso de la respuesta. La voluntad conserva esta dualidad de la traición y de la fidelidad, tengo la posibilidad de matar pero la fidelidad me abre al otro. La fidelidad se adquiere por medio del arrepentimiento, la oración ${ }^{9}$ y el perdón. Mi responsabilidad abre un espacio de tiempo que aplaza el momento de la muerte.

Smith parte del principio que naturalmente el hombre se cuida de sí antes que cuidarse de los demás (T.S.M., 385). Smith observa que la muerte de personas lejanas

9 La oración que es "la palabra privilegiada en la cual la voluntad busca su fidelidad a sí mismo" (T.I., 218, trad. personal). 
puede no afectar mayormente a uno mismo, uno tiende a ser más preocupado por sus propias dolencias.

Si fuese perder su dedo menique mañana, no podría dormir esta noche; pero siempre que no los haya visto nunca, roncará con la más profunda seguridad ante la ruina de cien millones de semejantes y la destrucción de tan inmensa multitud claramente le parecerá algo menos interesante que la mezquina desgracia propia (T.S.M., 253).

Sin embargo, en otros ejemplos, como en la relación de la madre con su niño enfermo, el cuidado del otro es natural, por la proximidad y cercanía, y propende además a favorecer una inquietud excesiva de parte de la madre por la muerte posible del niño (T.S.M., 54). Así, "es extraño que un niño muera sin que a alguien se le parta el corazón" (T.S.M., 386). La vejez o la enfermedad suscitan una repulsión natural, no obstante "para los virtuosos y los humanitarios las enfermedades de la vejez no son objetos de menosprecio y aversión" (T.S.M., 386). Smith además recurre de manera más amplia al principio de la solidaridad humana que nos conduce a sentir simpatía por la persona oprimida o lesionada por otra, y esforzarse en ayudarla (T.S.M., 154). La benevolencia es el movimiento bondadoso hacia el otro y "la bondad engendra bondad, y el ser queridos por nuestros semejantes es la meta principal de nuestra ambición, la forma más segura de lograrlo es mostrar mediante nuestra conducta que realmente lo queremos" (T.S.M., 395).

Lévinas aborda el cuidado desde la aparición del rostro, mientras que Smith aborda el cuidado desde la simpatía. En esto se puede distinguir la ética de Lévinas ${ }^{10}$ y oponerla de alguna manera a la simpatía de Smith, ya que el punto de partida es para el otro "La epifanía del rostro es ética" y no una constitución del otro por mí al modo de "meterse en los zapatos del otro". Lévinas, presenta una responsabilidad independiente de la aprobación o desaprobación de su conducta. Además, a los ojos de Lévinas la preocupación por la muerte del otro o el "morir por él" importa más que la prioridad relativa a la muerte propia "auténtica"11 (E.N., 240). Smith parte más bien del cuidado de sí, antes del cuidado del otro, aunque los considere también en forma concomitante. Pese a estas distinciones notorias se puede observar que ambos autores apelan al respeto y a la igualdad, debidos a todo ser humano. www.iep.utm.edu/emp-symp/

11 La muerte "auténtica”, Lévinas se refiere a Heidegger, cf. Kemp, P. (1993) "La crainte pour autrui". 


\section{¿El miedo a la muerte no será lo que conduce a proteger la vida?}

Lévinas inscribe todo sujeto en la fraternidad, que los hombres sean hermanos no se añade al hombre como conquista moral sino que es constitutivo de su ipseidad. "Porque mi posición como yo se afana en la fraternidad, el rostro se presenta a mí como rostro" (T.I., 313). El otro del cual me hago responsable es, a su vez, solidario con los demás, esto constituye el orden social, donde aparece el nosotros. La fecundidad surge de esta unidad del yo en lo colectivo sin disolución, sin retorno en sí, una unidad que atesta la posibilidad de la multiplicidad, la engendra. La ética es fundamental para preservar en las relaciones humanas la respuesta de cada uno al rostro del otro, y lleva en su seno el riesgo dramático de la muerte, la pregunta de la nada de la muerte, que resuelve en la responsabilidad que resguarda la humanidad en cada uno. El yo y el otro, en su unicidad abren al mismo que es común a la humanidad. El otro violenta mi tranquilidad y puede suscitar la violencia, la conciencia de lo dramático de la muerte como posibilidad, que se presenta como posibilidad en el rostro del otro, obliga a la vigilancia, y desgarra el yo de su egoísmo dándole de responder a la llamada. Esta responsabilidad "no es la privación del saber de la comprensión y la aprehensión, sino la excelencia de la proximidad ética de la socialidad, en su amor sin concupiscencia" (E.N., 178). Lévinas, criticando a Heidegger, dice que para que la humanidad sea auténtica tiene que ser des-intere-sada. El des-interés se mide en la caridad fraterna, la misericordia, la preocupación por el prójimo. El perdón es el bálsamo en las relaciones humanas, donde la responsabilidad siempre tiene su carga de culpabilidad. Para valorar el beneficio de la responsabilidad, Lévinas describe este acto como una liberación de la psiche, una respiración para el yo que se abre al Infinito. La ética de Lévinas propone una relación con el otro que se desprende de todo poder, incluso de toda intencionalidad. La epifanía del rostro del otro es ética. La obligación y la llamada ética del otro en su desnudez, su pobreza, su sufrimiento, me destituye de mi yo egoísta, pidiéndome la respuesta. La humanización crece en la medida de la respuesta de cada uno por el otro, hasta en su muerte y por su muerte.

Cuando Smith cierra el capítulo II, sección I, diciendo que "el pavor de la muerte aflige y mortifica al individuo pero protege y resguarda la ciudad" (T.S.M., 56), pone de relieve el interés de protegerse de lo peor que pueda pasar para sí y para el otro, o sea, su muerte. Smith saca esta conclusión después de haber descrito la simpatía con los muertos. De lo dramático de la muerte y de las consecuencias morales que conllevan: la justicia debida al muerto, el reconocimiento de sus méritos o la necesidad de castigar al culpable, el sufrimiento de los sobrevivientes, Smith explica el papel del pavor de la muerte. El temor de la muerte actúa de forma heurística, resguardando y protegiendo la ciudad, en la práctica, obligando a los seres humanos a evitar este mal, para sí y para los demás. Si el miedo de la muerte es tormentoso para el individuo, ya que apena, entristece, mortifica las pasiones, hay un beneficio para la vida en común. La indignación, incluso la del espectador, "propende a ser avivada por las consecuencias reales de las acciones" (T.S.M., 209). Así, el hombre que arroja una piedra sin prestar cuidado y mata a alguien sin quererlo será juzgado según la pena capital "aunque ello es sin duda excesivamente severo, no resulta totalmente incompatible con nuestros sentimientos 
morales" (T.S.M., 209). El cuidado de sí y de otro viene de la toma de conciencia de la gravedad de la muerte y promueve aplazarla, o evitarla para sí y para los demás. Smith confirma que tanto el cuidado de sí mediante la prudencia como el cuidado de los otros mediante la justicia y la beneficiencia son necesarios para una vida feliz con y para los otros (T.S.M., 451). Cuando existe la solidaridad o la "ayuda mutuamente proporcionada" donde reina amor, gratitud, amistad y estima, la sociedad "florece y es feliz" (T.S.M., 182). Así, los miembros de la sociedad están unidos por "los gratos lazos del amor y el afecto" (T.S.M., 182), y tienen como mira una felicidad común.

Ambos autores aciertan en que el miedo de la muerte para sí y para el otro es determinante en la moral y en la ética y conviene ejercitarse para domar el miedo o transformarlo en cuidado de sí y de los demás. Lévinas, sin embargo, apunta a la salvaguardia de la humanidad y a la paz, mientras que Smith ${ }^{12}$ propone también una ética con una perspectiva teleológica de felicidad en algo semejante a la proposición aristotélica $^{13}$, aunque su ética parezca principalmente deontológica. Smith se refiere a "Aristóteles, en las partes prácticas de su Ética" (T.S.M., 559) cuando describe la forma habitual de la conducta en relación con la virtud.

\section{¿Cuál es la función de la justicia natural, cómo se expresa?}

Lévinas hace referencia en algunas oportunidades a la interdicción del homicidio como dato universal y en particular al mandamiento que se encuentra en el decálogo "No matarás" (EX 20,13). Pero cuando alude al mandamiento, en general este se desprende del encuentro con el otro, y es el otro el que le impone el mandamiento por su misma presencia. "Este infinito, más fuerte que el homicidio, nos resiste ya en su rostro, es la expresión original, es la primera palabra: "No cometerás homicidio" (T.I.,217, trad. personal). El yo tiene este poder, esta "libertad salvaje y cándida" de matar al otro que le toma su lugar en el sol, que lo violenta en su tranquilidad. Pero la aparición del rostro se opone al asesinato ${ }^{14}$. Lévinas esgrime que en una sociedad de semejantes entre sí, dotados de razón, y cuya razón promete la paz, se insinúa el imperativo en la relación de uno con otro: "No matarás", que surge del rostro del otro y tiene que tenerme como destinatario exclusivo. Mi respuesta es un acto de solidaridad incomparable y único que abre a la fraternidad. Además, Lévinas observa que "existe la angustia de una responsabilidad que incumbe a los individuos que sobreviven a la muerte violenta de

12 Carrasco, A. (2004-2005). Teoría moral de Adam Smith, p. 37-38.

13 Cf. Ética a Nicómaco, Aristóteles. En el capítulo IV, \&1, Aristóteles precisa que en toda acción, en toda decisión $\pi \rho o \alpha i \rho \varepsilon \sigma l \varsigma$, el bien es el fin que se persigue y que es con vista a este fin que se dirigen las acciones.

14 "El infinito paraliza el poder por su resistencia infinita al homicidio, que, duro e invencible, reluce en el rostro del otro, en la desnudez total de sus ojos, sin defensa, en la desnudez de la apertura absoluta del trascendente" (T.I., 217, trad. personal). 
las víctimas" (E.N., 224). Como si cada cual aún inocente y con sus manos limpias tuviese que responder del crimen.

Smith parte más bien de los sentimientos que surgen en situaciones de muerte, analizando las reacciones y emociones que se desprenden en tales circunstancias. Si Smith admite que el cuidado empieza consigo mismo, no puede ir más allá de usurpar o derribar la felicidad de los demás por un bien propio mayor (T.S.M., 177). El grado del ultraje define el grado de enojo, el grado de indignación simpatizadora y el grado de culpa del agente, que tiende a ser proporcionalmente relacionado. El mayor es el máximo daño que se puede causar y contribuye al mayor grado de rencor de los sobrevivientes ${ }^{15}$. Pero dada la realidad de la naturaleza humana con sus pasiones, resentimientos, sin justicia como "pilar fundamental en el que se apoya todo el edificio" (T.S.M., 183), la sociedad puede decaer en la destrucción completa. La justicia como virtud permite el trato de uno con otro, como igual. Se distingue para Smith (Pico 2014, 371) la justicia como virtud y la justicia de la jurisprudencia. Smith apela incluso al consuelo de la creencia en una vida futura para una justicia en el cielo en caso que no se haya conseguido en la tierra (T.S.M., 190).

\section{¿Cómo interviene la justicia, el derecho positivo, frente al homicidio?}

Según Lévinas, "el homicidio solo pretende la negación total” (T.I., 216). Con la responsabilidad evito este daño inconmensurable a otro. Para explicar el concepto de responsabilidad Lévinas frecuentemente menciona el pasaje bíblico (Gen. 4,9) donde Dios pide a Caín: “¿Dónde está tu hermano?” Caín, celoso, ha matado a su hermano menor Abel porque Yahvé miró con agrado su ofrenda y no la suya, se disculpa devolviendo una pregunta injustificable: “¿Seré el guardián de mi hermano?” La justicia viene como tercero para asegurar con sus leyes la protección de todos según sus derechos (E.N., 132). La justicia controlada por el derecho positivo permite defender a los vulnerables y defender a las víctimas. La justicia aparece tarde en su obra ya que no considera que el derecho positivo, que tiende a asegurar la justicia, prime. Lévinas dice que "la justicia nace del amor" (E.N., 133) y que "el amor debe siempre vigilar a la justicia" (E.N., 133). Esta regulación de la justicia por el amor es muy importante para Lévinas, hasta que "yo soy responsable del otro incluso cuando comete crímenes, incluso cuando otros hombres cometen crímenes" (E.N., 133). La justicia tiene que reajustar su ética en un esfuerzo continuo, mediante la razón y acercándose a la bondad de la que proviene. La esperanza es infinita, el verdadero objeto de esperanza es la salvación. Es el efecto inmensamente misterioso de la compasión. "Esperar es luego esperar la reparación de lo irreparable, es entonces esperar para el presente" (E.E, 149, trad. personal). No

15 Smith explica esto aportando esta suposición, que es fundamental para la teoría de la simpatía, que un elemento esencial en la alegría humana es la alabanza, la atención y el respeto de sus prójimos, un ataque de la reputación de una persona pone en peligro este respeto y es, por lo tanto, profundamente resentido (Campbell 2010, 194, trad. personal). 
hay justicia que pueda reparar el agravio del homicidio, solo queda esta frustración de reparación imposible, por la cual solo la eternidad puede ser el lugar de la salvación. El perdón, para Lévinas, encuentra su legitimidad en el amor misericordioso o la bondad del Eterno. El perdón actúa sobre este pasado no para olvidarlo sino para conservarlo, purificarlo y permitir la renovación. Es lo propio de la expiación que es una forma extrema de la responsabilidad para el otro.

Para Smith, el "asesinato es el más atroz de todos los crímenes que afectan a los individuos, tanto a los ojos de la humanidad como a los de los individuos, tanto a los ojos de la humanidad como a los de la persona que lo comete" (T.S.M., 179). El culpable del asesinato merece castigo, ya que perturba el orden público, merece ser expulsado y esto permite la educación de los demás, que aterrorizados por lo que le resulta, no harán lo mismo (T.S.M., 186). Smith mesura el daño y no se opone a la corrección por la pena de muerte, incluso en el caso de provocar la muerte de alguien en forma accidental y aunque se pueda compadecer con el agente, porque no hay peor daño que la muerte. Smith avisa que hay que estar atento al espectador imparcial, el hombre en el pecho, el ejercicio del juicio moral necesita esfuerzo constante, reajuste reiterado, ejercicio de la conciencia y discernimiento. Smith así decreta que parece obvio que no puede haber mayor daño que el que se hace a un niño, sin embargo:

El abandono, es decir, el asesinato de niños recién nacidos era una práctica permitida en casi todos los estados de Grecia (...) En los últimos tiempos de Grecia, empero ello fue permitido con vistas a interese o conveniencias remotas, lo que no es excusable en absoluto. (...) Cuando la costumbre puede ratificar una violación de la humanidad tan espantosa, cabe imaginar que no hay ninguna práctica tan brutal que no sea capaz de autorizar (T.S.M., 363).

Smith concibió que podemos tener una tendencia a la insensibilidad de la muerte de otros y mayormente si son desconocidos y lejanos, sin embargo preconiza la vigilancia de la conciencia para que pueda indignarse justamente de las atrocidades o barbaridades que puedan existir.

Ambos autores condenan el asesinato, mayormente el daño que provoca la muerte del inocente. Lévinas inserta el mandamiento "no matarás" en la epifanía del rostro y su ética lleva en esto la particularidad de las éticas cristianas o hebraicas. Anscombe (1958, 8-9), en vez de descartarlas por esto de las otras éticas, propone la posibilidad de motivar a atenuar la diferencia y considerar estas éticas en su conjunto. En caso de daño irreparable, Lévinas apela a la culpabilidad, la corrección, la expiación, pero la justicia tiene que obrar conforme al amor sin concupiscencia ${ }^{16}$ con el perdón y la

16 "La responsabilidad para con el prójimo, que es, sin duda, el nombre severo de lo que llamamos amor sin Eros, caridad, amor en el que el instante ético domina sobre el instante pasional, amor, por tanto, sin concupiscencia". Lévinas, E., "Filosofía, justicia y amor", Topologik. Revista International de ciencias de la filosofía. Study filosofici. №6. 2009, p. 1. Web: http://www.topologik.net/LEVINAS_Topologik_6.pdf 
misericordia. Smith aplica, a primera vista, en caso de daño mortal una justicia rígida, implacable, que tiene que restituir el mal mayor por el castigo y así educar para prevenir toda recurrencia de daño similar. En una oportunidad, Smith descalifica en algo el objeto de piedad que puede ser el culpable, castigado a la pena de muerte, para los generosos y humanitarios, no hay que olvidar el interés de la sociedad y del orden general que prima (T.S.M., 186). En otra oportunidad, sin embargo, decreta que "la nobleza del perdón parece en muchas ocasiones superior incluso a la más absoluta corrección del enojo" (T.S.M., 419). Además, Smith advierte que en ningún país las leyes vigentes son iguales, entonces, conviene tratar de ajustarlas constantemente.

\section{¿Cómo se realiza la protección de la vida para sí y para los demás?}

Lévinas confirma que la clave se encuentra en el amor que es originario, la justicia deriva del amor. El amor como Palabra de Dios no sale de la ideología, está escrita en el rostro del otro, en el encuentro con el otro. La Palabra me exige en el encuentro con el otro "ser responsable". La responsabilidad es intransferible. "La elección no es en absoluto un privilegio; es la característica fundamental de la persona humana, entendida como moralmente responsable" (Lévinas, "Filosofía, justicia y amor", 2009, 5). La justicia es necesaria para preservar la equidad, pero la caridad es principal. Lo que protege la vida es el sacrificio de uno por el otro, de allí surge la bondad que se propaga. El yo se encuentra plenamente en este desgarramiento que lo destituye de su egoísmo. La preocupación por el otro se traduce en vigilancia, Lévinas recurre a la imagen de insomnio para describir esta inquietud permanente.

Para Smith, el desorden y la confusión son objetos de aversión y lamenta todo lo que tienda a generarlos. Smith es consciente de que el interés de cada uno está relacionado con la prosperidad de la sociedad y que la felicidad depende de la preservación de la existencia. La preservación de la vida se obtiene mediante el cuidado de sí y el cuidado del otro, o sea, por un lado practicando la virtud y por otro lado practicando la justicia, la benevolencia y la beneficiencia para los otros. Las relaciones con los demás apelan a un esfuerzo continuo de adecuación del juicio del espectador imparcial, acercándose así lo más posible al ideal moral. La justicia como "ley sagrada" motiva a actuar en favor de la justicia y para Smith la justicia no es solo el deber de corrección sino que el sentido de justicia que es previo a la acción y que orienta a actuar considerando a los otros como iguales y con respeto.

Ambos autores promueven la protección de la vida. Es interesante de observar que también coinciden en sus reflexiones relativas al suicidio. Los argumentos son distintos, pero para ambos al final y al cabo, el suicidio no es aconsejable ni propende a la protección de la vida. Ambos avisan del daño mayor causado, por el suicidio, a la vida misma y a los sobrevivientes. Lévinas se opone categóricamente al suicidio que lleva en sí una contradicción, ya que cuando la voluntad consiente al suicidio no resuelve la prueba suprema de la voluntad y de la libertad que es el sufrimiento. Por 
el suicidio el yo se encierra en su egoísmo y se condena a sí mismo. La paciencia ${ }^{17}$ es en medio del sufrimiento la apertura de la voluntad para querer como deseo y bondad que nada limita. Smith (T.S.MS, 489) ${ }^{18}$ no sigue las posiciones de Hume ${ }^{19}$ respecto al suicidio: "La naturaleza, en su estado recto y saludable, nunca nos impele al suicidio".

\section{Conclusión}

La muerte viene a poner a prueba la moral y la ética, Moreland, J.P. \& Norman L. Geisler (1990) intentan ver cuáles son las posiciones morales destacadas en los debates sobre la vida y la muerte en bioética. La confluencia y divergencia de opiniones o convicciones morales aumentadas por la globalización fomentan y dificultan las discusiones o resolución de problemas en bioética. La mirada del tema desde la ética de Lévinas permite poner a la luz la relevancia del tema para Smith, aunque el enfoque de Lévinas sea fenomenológico. Adam Smith desarrolló su teoría de los sentimientos morales a partir de una relación con los demás, descrita en forma empírica. La muerte no es central en su teoría, como lo es en Lévinas, sin embargo tiene una incidencia en la formación de los sentimientos morales que merece consideración, ya que puede también aportar en reflexiones o debates éticos relativos a la vida y a la muerte. En efecto, Smith aborda la muerte en situaciones concretas diversas en múltiples ejemplos que permiten un amplio panorama sobre el tema. Su posición no es siempre muy definida y refleja en algo el propósito mismo de la teoría de los sentimientos morales, no se fija en posiciones dogmáticas sino que entabla un método para favorecer el desarrollo y aptitud de cada uno para tener un juicio moral lo más ajustado posible. Las virtudes, en particular la de prudencia para el cuidado de sí, la justicia y la benevolencia y la beneficiencia para el cuidado del otro tienden a favorecer una vida feliz para sí y para los otros, responden a la necesidad de tomar en cuenta que los seres humanos tienen que ser tratados como iguales y con respeto. Su método preconiza recurrir al espectador imparcial u "hombre dentro del pecho" que permite pasar de una simpatía pre-moral a una simpatía moral que trata de acercarse lo más posible a la perfección. Si la búsqueda de felicidad es más relevante que la de la protección de la vida, en Smith se puede sin embargo observar que con su teoría la favorece, ya que trata de evitar lo peor que pueda pasar al alguien, o sea su muerte, por lo dramático que conlleva el hecho para sí o para otro. El miedo

Cf. T.I., 267.

18 "La naturaleza, en su estado recto y saludable, nunca nos impele al suicidio. () Las personas infelices que perecen de este modo tan desdichado no son objetivos propios de crítica sino de conmiseración. Pretender castigarlos cuando están fuera del alcance de cualquier sanción humana no es tan absurdo como injusto" (TSM, 489).

19 Cf: Muñoz Saldaña, R. (2003, 213). "David Hume: del suicidio y de la inmortalidad del alma": "El mandamiento: "No matarás" significa, evidentemente, solo el matar a otros, sobre cuyas vidas no tenemos autoridad. De esta manera, el poder de suicidarse es una ventaja que los hombres poseen aun sobre la Deidad misma". 
de la muerte, o "pavor" de la muerte, tiene un impacto y determina la necesidad de ejercitar las virtudes para domarlo y del cuidado para sí y del otro. El mandamiento "no matarás" que surge del encuentro con el rostro, para Lévinas salvaguarda la vida y la humanidad y tiene una función preventiva. Si la posición de Smith respecto de la pena de muerte muestra, a mi parecer, los límites de su método, sin embargo la simpatía favorece la aparición de reacciones morales retroactivas respecto de la muerte de otro, y el ejercer el juicio moral lo más perfectamente posible puede tender paulatinamente a una meta preventiva. Las reacciones de Smith sobre el infanticidio, por ejemplo, lo muestran. Lévinas, con sus reflexiones profusas relativas al tema de la muerte y su función protectora en ética, y Smith, con sus anotaciones esparcidas enraizadas en situaciones concretas, nos ofrecen materiales para alimentar las reflexiones y debates relativos a la muerte y a la protección de la vida.

\section{Referencias bibliográficas}

Anscombe, G.E.M. (1958), “Modern Moral Phylosophy”, Philosophy 33, №124, January 1958.

Campbell, T.D. (2010), Adam Smith's science of moral (2a ed.). New York: Routlage.

Canto-Sperber, M. (2004), Dictionnaire d'éthique et de philosophie morale (2 $2^{\mathrm{a}} \mathrm{ed}$.). Paris: PUF Quadrige. "Lévinas", "Smith", "Sympathie", "vie et mort".

Carrasco, A. (2004-2005), "La teoría moral de Adam Smith", Seminarios de Filosofía, vol 17-18.

Dutrait, F. (2008), "La morale, sympathie, utilité et finalité dans la morale de Smith", Revue numérique Philopsis. Web: http://www.philopsis.fr/IMG/pdf_morale_ smith_dutrait.pdf

Echeverría, J. (2013), El morir como pauta ética. Santiago: JC. Saer Editor.

Feron, E. (1999), Phénomenologie De La Mort: Sur Les Traces De Lévinas. Kluwer Academic Publishers.

Frierson, P.R. (December 2006), “Adam Smith and the Possibility of Sympathy with Nature". Pacific Philosophical Quarterly Volume 87, Issue 4, 442-480, DOI: 10.1111/j.1468-0114.2006.00271.x Web: http://people.whitman.edu/ frierspr/ smith2.htm

Giannini, H. (1998), Livre I, chapitre XIX. El Mercurio, 25 de junio de 1998.

Internet Enciclopedia of philosophie IEP. Empathy and sympathy in Ethics. 3.B: "Adam Smith's Philosophy of Sympathy". 4.C: "Ethics Against Empathy in Levinas". Web: http://www.iep.utm.edu/emp-symp/

Kemp, P. (1993), “La crainte pour autrui”, Philosophica 52 (1993, 2): 49-61.

Lévinas, E. (2009), Totalité et Infini. [T.I.], Essai sur l'extériorité. (12ª ed.). Paris: Presse Offset.

(2009), "Filosofía, justicia y amor", Topologik. Revista International de ciencias de la filosofía. Study filosofici. $\mathrm{N}^{\circ} 6$. Web: http:/www.topologik.net/ LEVINAS_Topologik_6.pdf 
(2008), Ethique et infini [E.I.], (14 ${ }^{\mathrm{a}}$ ed.). Paris: Fayard.

(1995), Altérité et transcendance [A.T]. Montpellier: Fata Morgana, coll. "Essais".

(1994), Dios, la muerte y el tiempo. [D.M.T]. Madrid: Catédra.

(1993), Entre nosotros. Ensayos para pensar en otro [E.N]. (Trad. José Luis Pardo). Valencia: Luis Santangel.

(1991), La mort et le temps [M.T]. Paris: L'Herne, collection Livre de Poche.

(1986), “De l'existence à l'existant”. Vrin, p. 147-174. Web : http:// palimpsestes.fr/textes_philo/levinas/Levinas_De-l'existence-a-l'existant.pdf NIjhoff.

(1977), Autrement qu'être, ou au-delà de l'essence [A.E.]. La Haya:

Montaigne (2009), Essais. Paris: Broché. Livre I, chapitre XIX.

Moreland, J.P., Norman L. Geisler (1990), The life and death debate, moral issues of our time. Greenwood publishing group, USA.

Muñoz Saldaña, R. (2003), "David Hume: del suicidio y de la inmortalidad del alma", Perfiles Latinoamericanos, núm. 21, diciembre 2003: 211-214 Facultad Latinoamericana de Ciencias Sociales Distrito Federal, México.

Parra, F. (2009), "El tiempo, el otro y la muerte a través de Emmanuel Lévinas", Teologia y Vida. Vol L, N³, III semestre.

Pico, A. (2014), "Sentimiento moral y razón: la noción de justicia en Adam Smith y Amartya Sen", Cuadernos de Economía, vol. XXXIII, núm. 63, julioseptiembre 2014: 359-379. Universidad Nacional de Colombia: Bogotá, Colombia.

Rolland, J. (1995), “La mort en sa négativité”. Alocución pronunciada el 29 enero de 1996 en el gran anfiteatro de la Sorbonne, en homenaje a Emmanuel Levinas, fallecido el 25 décembre 1995. Revista electrónica Noesis 3/2000. Puesto en linea el 15 de Marzo 2004. Web: http://noesis.revues.org/8

Smith, A. (2009), Teoría de los sentimientos morales [T.S.M.]. (Trad. Carlos Rodriguez Braun, $3^{\mathrm{a}}$ ed.). Madrid: Alianza Editorial.

Smith, A. (1982), Essays on philosophical subjects. Oxford University Press: Ed. P.D. Wightman and J.C. Brice Liberty Fund Indianapolis.

Smith, A. (1963), Lectures on rethoric and belles lettres. Oxford University Press: Huge Blair, D.D. \& F.R.S. Oxford Library.

Torres Fierro, D. (2008), David Hume, Adam Smith. Dos testimonios trágicos, Claves de Razón Práctica, enero-febrero 2008, n¹79: 66-70. Web: http://www. elboomeran.com/upload/ficheros/noticias/claves179tfierro2.pdf m

West, E.G. (1976), Adam Smith, the man and his work. Liberty Fund: Indianapolis. 